\title{
Gastrointestinal regulation of food intake
}

\author{
David E. Cummings and Joost Overduin \\ Division of Metabolism, Endocrinology and Nutrition, Department of Medicine, University of Washington, \\ Veterans Affairs Puget Sound Health Care System, Seattle, Washington, USA.
}

\begin{abstract}
Despite substantial fluctuations in daily food intake, animals maintain a remarkably stable body weight, because overall caloric ingestion and expenditure are exquisitely matched over long periods of time, through the process of energy homeostasis. The brain receives hormonal, neural, and metabolic signals pertaining to body-energy status and, in response to these inputs, coordinates adaptive alterations of energy intake and expenditure. To regulate food consumption, the brain must modulate appetite, and the core of appetite regulation lies in the gut-brain axis. This Review summarizes current knowledge regarding the neuroendocrine regulation of food intake by the gastrointestinal system, focusing on gastric distention, intestinal and pancreatic satiation peptides, and the orexigenic gastric hormone ghrelin. We highlight mechanisms governing nutrient sensing and peptide secretion by enteroendocrine cells, including novel taste-like pathways. The increasingly nuanced understanding of the mechanisms mediating gut-peptide regulation and action provides promising targets for new strategies to combat obesity and diabetes.
\end{abstract}

\section{Principles of satiation}

"Satiation" refers to processes that promote meal termination, thereby limiting meal size $(1,2)$. "Satiety" refers to postprandial events that affect the interval to the next meal, thereby regulating meal frequency, which is also influenced by learned habits (3). Satiation results from a coordinated series of neural and humoral signals that emanate from the gut in response to mechanical and chemical properties of ingested food. Although the relevant signals are commonly dubbed "satiety signals," this term is usually a misnomer, because most of them promote termination of ongoing meals and do not delay subsequent meal initiation or affect intake if delivered between meals (4).

A primary function of the gut is to achieve efficient nutrient digestion and absorption; many satiation signals optimize these processes by influencing gastrointestinal (GI) motility and secretion. Their additional capacity to limit meal size enhances this control by restricting the rate at which nutrients reach the gut (5). Meals are typically stopped long before gastric capacity is reached, and when food is diluted with noncaloric bulking agents, the volume ingested increases to maintain constant caloric intake (6). Therefore, animals can consume much larger meals than they typically do. A major function of satiation is to prevent overconsumption during individual meals, thereby averting deleterious consequences from incomplete digestion as well as excessive disturbances in circulating levels of glucose and other nutrients (7).

Satiation signals arise from multiple sites in the GI system, including the stomach, proximal small intestine, distal small intestine, colon, and pancreas, each of which is discussed below (Figure 1 and Table 1). Ingested food evokes satiation by two primary effects on the GI tract - gastric distention and release of peptides from enteroendocrine cells. The hindbrain is the principal central site receiving input from short-acting satiation signals, which are transmitted both neurally (for example, by vagal afferents projecting to the nucleus of the solitary tract) and hormonally (for

Nonstandard abbreviations used: AGRP, agouti-related protein; AP, area postrema; APO AIV, apolipoprotein A-IV; CCK, cholecystokinin; CCK1R, CCK receptor 1; DPP4, dipeptidyl peptidase-4; FA, fatty acid; GI, gastrointestinal; GLP, glucagon-like peptide; GLP1R, GLP1 receptor; MCH, melanin-concentrating hormone; NPY, neuropeptide

Y; PP, pancreatic polypeptide; PYY, peptide YY.

Conflict of interest: The authors have declared that no conflict of interest exists. Citation for this article: J. Clin. Invest. 117:13-23 (2007). doi:10.1172/JCI30227. example, by gut peptides acting directly on the area postrema [AP], which lies outside the blood-brain barrier). Although the perception of fullness clearly involves higher forebrain centers, conscious awareness of GI feedback signals is not required for satiation. Even animals whose hindbrain is surgically disconnected from the forebrain exhibit satiation and respond to GI satiation peptides $(8,9)$. Therefore, gut-hindbrain communication is sufficient for satiation, although this normally interacts with higher cognitive centers to regulate feeding.

Pathways relaying short-acting satiation signals from the gut to the hindbrain also interact at several levels with long-acting adiposity hormones involved in body-weight regulation, such as leptin and insulin. Through multifaceted mechanisms, adiposity hormones function as gain-setters to modulate the sensitivity of vagal and hindbrain responses to GI satiation signals. Adiposity hormones thereby regulate short-term food intake to achieve longterm energy balance $(10,11)$.

Here we provide an overview of the regulation of feeding by gastric, intestinal, and pancreatic signals. We discuss interactions among these signals and between short-acting GI factors and long-acting adiposity hormones. We also highlight new insights regarding mechanisms by which enteroendocrine cells sense and respond to nutrients. The increasingly sophisticated understanding of these topics should help guide development of novel antiobesity therapeutics.

\section{Gastric satiation signals}

Densely innervated by sensory vagal and splanchnic nerves (12), the stomach is optimized to monitor ingestion. Long-standing evidence demonstrates that animals overeat with voluminous meals if food is drained from their stomach as they eat (13). This observation, however, does not specifically implicate the stomach as a source of satiation signals, because the exodus of ingesta through a gastric cannula also precludes meal-related signals that would normally arise from postgastric sites.

Evidence that the stomach itself contributes to satiation derives from experiments involving cuffs that can reversibly close the pylorus (the exit from the stomach) and prevent passage of food downstream. Studies using this model demonstrate that major gastric distention alone is sufficient to terminate ingestion, but the amount of food required for this exceeds that eaten in a typical meal $(2,14)$. 


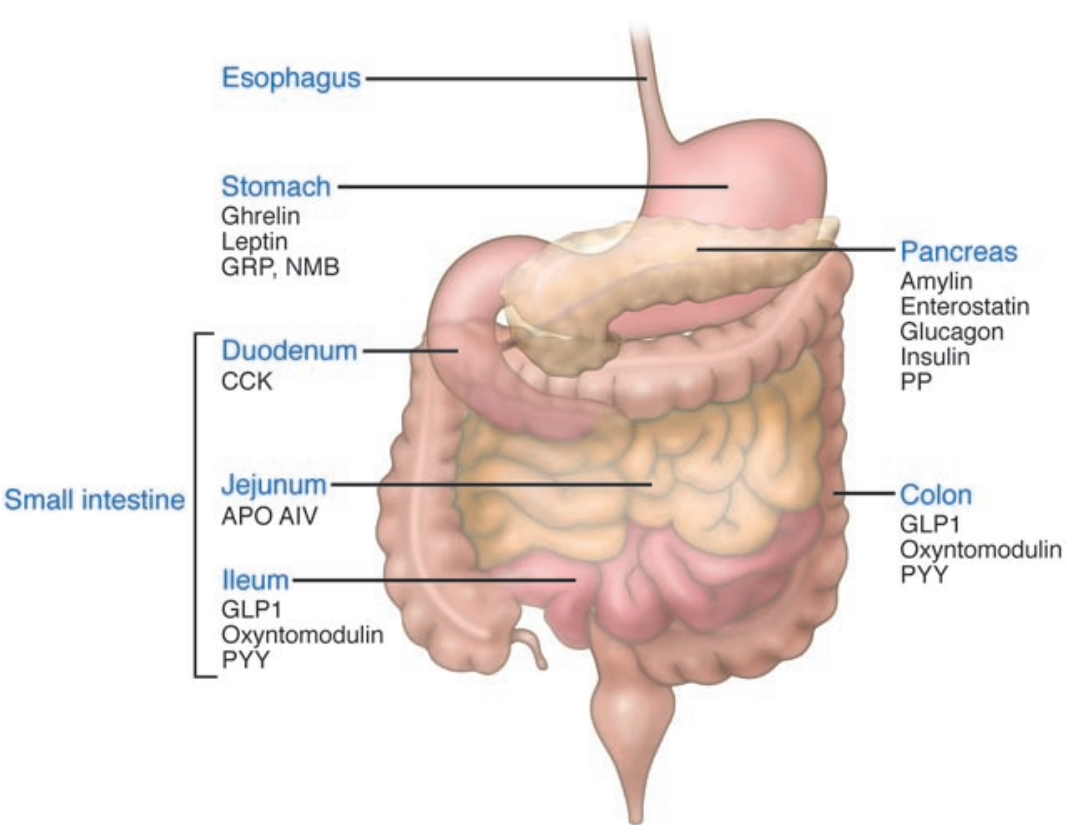

\section{Figure 1}

Principal sites of synthesis of Gl peptides implicated in the regulation of food intake. Depicted are the main locations of production for each peptide, although many of these molecules are detectable in smaller quantities at other sites in the Gl system. In addition, most of them are also synthesized within the brain, including CCK, APO AIV, GLP1, oxyntomodulin, $P Y Y$, enterostatin, ghrelin, gastrin-releasing peptide (GRP), neuromedin B (NMB), and possibly PP. GI peptides that regulate appetite and do not seem to be produced within the brain include leptin, insulin, glucagon, and amylin.
However, normal postprandial gastric distention does contribute to satiation when acting in concert with pregastric and postgastric stimuli $(2,14)$. Oral and gastric stimuli happen concurrently during eating, and up to $40 \%$ of a meal empties into the intestine before meal termination (15). Therefore, pregastric, gastric, and intestinal satiation signals commence almost simultaneously, and they function in unison, augmenting each other's satiating effects (14).

Gastric satiation signals arise primarily from mechanical distention, whereas those from the intestine derive largely from the chemical effects of food (16). Hence, with the pylorus closed, gastric loads limit ingestion solely on the basis of their volume, rather than their nutrient content, osmolarity, or $\mathrm{pH}$ (17). Although the stomach can sense nutrients (for example, to regulate gastrin release) (18), this does not seem to contribute to satiation. The stomach wall is endowed with discrete neural sensors of tension (19), stretch (20), and volume (14). Output from these mechanoreceptors is relayed to the brain by vagal and spinal sensory nerves $(14,21)$, using a complex array of neurotransmitters and neuromodulators, including glutamate, acetylcholine, nitric oxide, calcitonin-gene-related peptide, substance $\mathrm{P}$, galanin, and cocaine-andamphetamine-related transcript (14).

Bombesin-related peptides (for example, gastrin-releasing peptide and neuromedin B), which are produced by gastric myenteric neurons, can reduce food intake when delivered pharmacologically to humans and other animals (2). Because it is not clear, however, whether these peptides are regulated by ingested nutrients, they are not discussed in this review of meal-related GI signals.

\section{Intestinal satiation}

The generally accepted assertion that "gastric satiation is volumetric, intestinal satiation is nutritive" (16) reflects the importance of nutrients in mediating intestinal satiation, with a limited role for distention. Intestinal nutrient infusions reduce food intake in many species, including humans (14) - an effect that commences within seconds of nutrient infusion, indicating that at least some of the associated satiation signals emanate from the gut, rather than from postabsorptive sources (22). These, and other, findings demonstrate that the intestines play a dominant role in satiation. Many intestinal satiation signals inhibit gastric emptying, and this probably helps limit ingestion by enhancing gastric mechanoreceptor stimulation. However, sham feeding experiments show that a delay of gastric emptying is not required for intestinal signals to elicit satiation (14).

Mediators of intestinal satiation include a cadre of gut peptides that are secreted from enteroendocrine cells in response to ingested food. These messengers diffuse through interstitial fluids to activate nearby nerve fibers and/or enter the bloodstream to function as hormones (Figure 2). In conjunction with gastric distention, satiation peptides educe the perception of GI fullness, promoting meal termination. Standards for physiologically satiating peptides were articulated in the publication describing the first such agent, cholecystokinin (CCK) $(2,4)$. According to these criteria, a satiation factor should be released during food ingestion, and exogenous administration of it should decrease meal size in a dose-dependent manner - rapidly, transiently, and at physiologic concentrations, without causing illness.

\section{Upper-intestinal satiation: CCK}

CCK is the archetypal intestinal satiation peptide, first described as such three decades ago (4). It is produced by I cells in the duodenal and jejunal mucosa, as well as in the brain and enteric nervous system. Intestinal CCK is secreted in response to luminal nutrients, especially lipids and proteins. The CCK prepropeptide is processed by endoproteolytic cleavage into at least six peptides, ranging from 8 to 83 amino acids in length (23). The multiple bioactive forms pertinent to feeding share a common carboxy-terminal octapeptide with an $\mathrm{O}$-sulfated tyrosine. The major circulating moieties are CCK8, CCK22, CCK33, and CCK58, although recent evidence suggests that CCK58 might be the only relevant endocrine form in some species (24). CCK peptides interact with two receptors expressed in the gut and brain. CCK receptor 1 (CCK1R, formerly known as CCK-A, for "alimentary") predominates in the GI system, whereas CCK2R (formerly known as CCK-B, for "brain”) predominates in the brain. Through endocrine and/or neural mechanisms, CCK regulates many GI functions, including satiation. 
Table 1

Selected Gl and pancreatic peptides that regulate food intake

\begin{tabular}{|c|c|c|c|c|c|c|}
\hline \multirow[t]{2}{*}{ Peptide } & \multirow[t]{2}{*}{ Main site of synthesis } & \multirow[t]{2}{*}{$\begin{array}{l}\text { Receptors mediating } \\
\text { feeding effects }\end{array}$} & \multicolumn{3}{|c|}{$\begin{array}{c}\text { Sites of action of peripheral } \\
\text { peptides germane to feeding }\end{array}$} & \multirow[t]{2}{*}{$\begin{array}{c}\text { Effect on } \\
\text { food intake }\end{array}$} \\
\hline & & & Hypothalamus & Hindbrain & Vagus nerve & \\
\hline CCK & Proximal intestinal I cells & CCK1R & $x$ & $x$ & $\mathrm{X}$ & $\downarrow$ \\
\hline GLP1 & Distal-intestinal L cells & GLP1R & $X ?$ & $X ?$ & $X$ & $\downarrow$ \\
\hline Oxyntomodulin & Distal-intestinal L cells & GLP1R and other & $X$ & & & $\downarrow$ \\
\hline$P Y Y_{3-36}$ & Distal-intestinal L cells & $\mathrm{Y} 2 \mathrm{R}$ & $X$ & & $x$ & $\downarrow$ \\
\hline Enterostatin & Exocrine pancreas & F1-ATPase $\beta$ subunit & & & $X$ & $\downarrow$ \\
\hline APO AIV & Intestinal epithelial cells & Unknown & $x$ & & $x$ & $\downarrow$ \\
\hline PP & Pancreatic F cells & Y4R, Y5R & & $x$ & $x$ & $\downarrow$ \\
\hline Amylin & Pancreatic $\beta$ cells & CTRs, RAMPs & $x$ & $x$ & & $\downarrow$ \\
\hline GRP and NMB & Gastric myenteric neurons & GRPR & & $\mathrm{X}$ & $x$ & $\downarrow$ \\
\hline Gastric leptin & Gastric chief and P cells & Leptin receptor & $?$ & $?$ & $X$ & $\downarrow$ \\
\hline Ghrelin & Gastric X/A-like cells & Ghrelin receptor & $x$ & $x$ & $x$ & $\uparrow$ \\
\hline
\end{tabular}

CTRs, calcitonin receptors; RAMPs, receptor activity-modifying proteins; GRP, gastrin-releasing peptide; NMB, neuromedin B; GRPR, GRP receptor. X? indicates that it is unclear whether physiologically relevant quantities of GLP1 from the gut evade DPP4-mediated degradation in blood to activate GLP1 receptors in the brain, although these receptors might interact with CNS GLP1 to regulate food intake. ? indicates that it seems very unlikely that gastric leptin interacts in a physiologically meaningful way with leptin receptors in the hypothalamus or hindbrain, which are important targets of leptin secreted from adipocytes. AEffect of peripheral peptides on food intake. In some cases, central administration yields opposite results.

When peripherally injected immediately before a meal, CCK decreases meal size in a dose-dependent manner without affecting water intake or causing illness (4). Exogenous CCK also triggers a stereotyped sequence of behaviors that rats normally display upon meal completion, suggesting that it evokes the perception of satiation without internal food stimuli (25). Typifying a short-acting satiation signal, the anorectic effects of CCK are very short-lived and undetectable if the peptide is injected more than 30 minutes before meals.

Satiating effects of CCK have been confirmed in numerous species, including humans, in whom the carboxy-terminal octapeptide reduces meal size and duration (26). Pharmacologic and genetic experiments indicate that CCK1R mediates CCK-induced satiation $(27,28)$. This receptor is expressed on vagal afferents, and peripheral CCK administration increases vagal-afferent firing, as well as neuronal activity in the hindbrain region receiving visceral vagal input $(29,30)$. Furthermore, both subdiaphragmatic vagotomy and selective vagal deafferentation decrease the anorectic effects of peripheral CCK (31-33). These findings identify a critical vagal pathway for CCKinduced satiation. However, CCK1R is also expressed in the hindbrain and hypothalamus. Lesions of the hindbrain AP attenuate CCKinduced satiation (34), and CCK microinjections into several hypothalamic nuclei decrease food intake (35). These observations suggest that CCK might relay satiation signals to the brain both directly and indirectly, and/or that central CCK contributes to satiation.

As is mentioned above, CCK-induced satiation could result in part from inhibition of gastric emptying, thereby augmenting gastric mechanoreceptor stimulation. Some vagal-afferent fibers respond synergistically to gastric distention and CCK (36), and subthreshold doses of CCK reduce food intake in monkeys if combined with gastric saline preloads (37). Similarly, gastric distention augments the anorectic effects of CCK8 in humans (38). However, other studies show no differences in the satiating capacity of CCK8 between rats eating normally and those either sham fed or fitted with closed pyloric cuffs $(33,39)$. These and other observations indicate that CCK causes satiation through mechanisms additional to enhancing gastric distention signals.
The impact of eliminating CCK1R signaling supports a physiologic role for this receptor in satiation. Rats lacking CCK1R show increased meal size and gradually become obese (27), a phenotype possibly driven by overexpression of neuropeptide Y (NPY) in the dorsomedial hypothalamus (40). The obesity is fairly mild, however, and is not present in CCK1R-deficient mice (28); this is consistent with the proposed function of CCK as a short-acting satiation signal. CCK1R antagonists also increase meal size and food intake in experimental animals $(41,42)$, and they increase hunger, meal size, and caloric intake in humans (43).

Despite the role of CCK in terminating individual meals, its importance in long-term body-weight regulation and its potential as an antiobesity target are questionable. Chronic CCK administration in animals, with up to 20 peripheral injections per day, reduces meal size, but this is offset by increased meal frequency, leaving body weight unaffected (44). CCK administration decreases food intake acutely in humans by shortening meals (45), but anorectic effects dissipate after only 24 hours of continuous infusion (46). Not surprisingly, trials of CCK1R agonists as antiobesity therapeutics have been unsuccessful to date. The most important role for CCK in body-weight regulation might be its synergistic interaction with long-term adiposity signals, such as leptin (see below) $(10,11)$.

\section{Lower-intestinal satiation: glucagon-like peptide-1}

The ileal brake is a feedback phenomenon whereby ingested food activates distal-intestinal signals that inhibit proximal GI motility and gastric emptying (47). It is mediated by neural mechanisms and several peptides that are also implicated in satiation. These engage a behavioral brake on eating to complement the ileal brake, restraining the rate of nutrient entry into the bloodstream (5). One such peptide is glucagon-like peptide-1 (GLP1). It is cleaved from proglucagon, which is expressed in the gut, pancreas, and brain (48). Other proglucagon products include glucagon (a counterregulatory hormone), GLP2 (an intestinal growth factor), glicentin (a gastric acid inhibitor), and oxyntomodulin. Although several of these peptides are implicated in satiation, evidence is strongest for GLP1 and oxyntomodulin. 


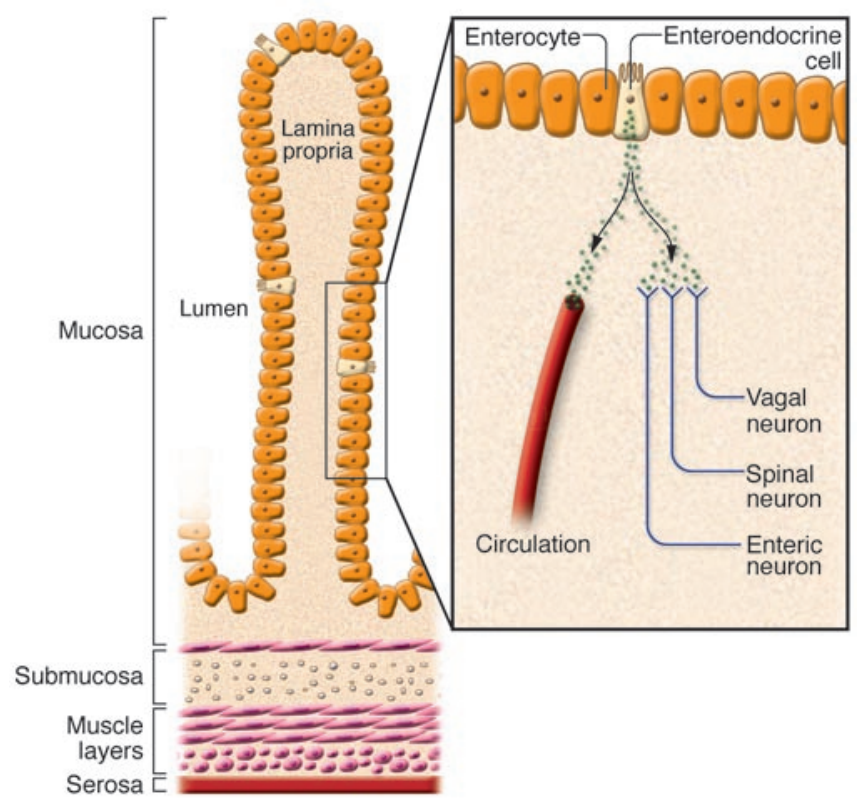

Figure 2

Topography of enteroendocrine cells and absorptive enterocytes on a villus within the small-intestinal wall. Enteroendocrine cells sense nutritive and non-nutritive properties of luminal food and, in response, release satiation peptides from their basolateral aspect. These signals diffuse through the lamina propria to activate nearby vagal- and spinalafferent fibers from neurons within the nodose and dorsal root ganglia, respectively, as well as myenteric neurons. Satiation peptides can also enter the bloodstream to act distantly as hormones. Gut-peptide release is regulated not only by luminal nutrients but also by somatic signals. The basolateral side of enteroendocrine cells bears receptors that respond to neurotransmitters, growth factors, and cytokines. Neurotransmitters mediate duodenal-ileal communication to regulate $L$ cell secretion, and they enable central modulation of gut-peptide release. Whether vagal- or spinal-afferent nerves are directly activated by ingested nutrients is uncertain. Although vagal- and spinalafferent fibers approach the abluminal aspect of enteroendocrine cells and enterocytes, they do not form synapse-like contacts with these epithelial cells, nor do they extend to the intestinal lumen. Some subepithelial nerve fibers might respond to luminal chemicals that diffuse across the epithelium, such as FAs, but this applies only to short-chain FAs, which do not efficiently elicit satiation (116). Other vagal-afferent fibers respond selectively to intestinal carbohydrates or fats. Although it is theoretically possible that these neurons sense nutrients in the extracellular space, it is more clearly established that signaling molecules released from enteroendocrine cells mediate macronutrientspecific neural activation.

GLP1 is produced primarily by L cells in the distal small intestine and colon, where it colocalizes with oxyntomodulin and peptide YY (PYY). Ingested nutrients, especially fats and carbohydrates, stimulate GLP1 secretion by indirect, duodenally activated neurohumoral mechanisms, as well as by direct contact within the distal intestine (49). The two equipotent bioactive forms, GLP1 $1_{7-36}$ amide and GLP1 $1_{7-37}$, are rapidly inactivated in the circulation by dipeptidyl peptidase-4 (DPP4) (50). In addition to engaging the ileal brake, GLP1 accentuates glucose-dependent insulin release, inhibits glucagon secretion, and increases pancreatic $\beta$ cell growth (48). Therefore, DPP4-resistant GLP1 congeners are being developed to treat diabetes.
GLP1 decreases food intake in several species $(51,52)$, including humans (53). Peripheral injections elicit satiety among normal-weight (54), obese (55), and diabetic (56) persons. Importantly, patients with diabetes treated with either GLP1 or the GLP1 receptor (GLP1R) agonist exenatide lose weight progressively in trials lasting up to two years $(57,58)$. This is especially remarkable because improved glycemic control achieved with other agents typically promotes weight gain.

The mechanisms underlying GLP1-induced anorexia are not fully known but involve vagal and possibly direct central pathways. Anorectic effects are mediated specifically by GLP1R, as they are absent in GLP1R-deficient mice and are reversed with selective GLP1R antagonists (59). GLP1R is expressed by the gut, pancreas, brainstem, hypothalamus, and vagal-afferent nerves (48). The vagus is required for peripheral GLP1-induced anorexia, which is abolished by vagal transection or deafferentation $(60,61)$. Whether peripheral GLP1 also functions through central receptors is questionable. The peptide can cross the blood-brain barrier, but it seems unlikely that physiologically relevant quantities of endogenous peripheral GLP1 evade peripheral DPP4 degradation and penetrate the brain. However, GLP1 is produced by brainstem neurons that project to hindbrain and hypothalamic areas germane to energy homeostasis, possibly regulating appetite. Activation of hypothalamic GLP1R decreases food intake without causing illness, whereas GLP1R activation in the amygdala elicits malaise (62). Although pharmacologic use of exenatide can stimulate the illness pathway, nausea is not the only mechanism reducing food intake. There is little correlation between the severity of nausea and the amount of weight lost, and doses of exenatide too low to cause nausea do promote weight loss.

Although GLP1 administration can reduce food intake, the physiologic importance of GLP1 in feeding was challenged by the observation that GLP1R-deficient mice have normal food intake and body weight (63). Regardless of its physiologic significance in energy homeostasis, GLP1R overstimulation offers an attractive pharmacologic antiobesity strategy, because it reduces body weight while independently ameliorating diabetes.

\section{Lower-intestinal satiation: oxyntomodulin}

Like GLP1, oxyntomodulin is a proglucagon-derived peptide secreted from distal-intestinal L cells in proportion to ingested calories. In rodents, exogenous administration decreases food intake while increasing energy expenditure, and chronic injections reduce body-weight gain $(64,65)$. In humans, i.v. infusion acutely lessens hunger and single-meal food intake (66), and repeated injections decreased body weight by $0.5 \mathrm{~kg} /$ wk more than placebo in a 4-week trial (67). In this study, oxyntomodulin reduced buffet-meal intake (without decreasing palatability) by $25 \%$ at the beginning of the trial and by $38 \%$ at the end, indicating no tachyphylaxis. Replicating animal results, the regimen also increased activity-related energy expenditure (68).

Although the mechanisms mediating these effects are enigmatic, GLP1R is probably involved, since oxyntomodulin does not alter feeding in GLP1R-deficient mice (59), and the GLP1R antagonist exendin $_{9-39}$ blocks oxyntomodulin-induced anorexia (64). Additional pathways are implicated, however, as oxyntomodulin binds GLP1R 100 times less avidly than GLP1 does, yet they elicit anorexia at equimolar doses (64). The peptides also have different CNS targets - oxyntomodulin activates neurons in the hypothalamus (65), whereas GLP1 does so in the hindbrain and other autonomic 
control areas (69). Moreover, intrahypothalamic exendin ${ }_{9-39}$ inhibits anorectic effects of oxyntomodulin but not GLP1 (65), and studies with GLP1R-deficient mice indicate that the two peptides differentially regulate feeding and energy expenditure (59).

The crystal structure of oxyntomodulin has been solved, and this advance should facilitate the rational design of oxyntomodulin peptidomimetics to be tested as oral antiobesity pharmaceuticals.

\section{Lower-intestinal satiation: PYY}

The pancreatic polypeptide-fold (PP-fold) family includes PYY, NPY, and PP. All are 36-amino acid peptides that require carboxyterminal amidation for bioactivity and share the PP-fold structural motif. They interact with a family of receptors (Y1R, Y2R, Y4R, Y5R, and Y6R) that couple to inhibitory G proteins. NPY is an orexigenic hypothalamic neuropeptide; PP is discussed below.

PYY is produced mainly by distal-intestinal L cells, most of which coexpress GLP1. It is secreted postprandially in proportion to caloric load, with a macronutrient potency of lipids being greater than that of carbohydrates, which is greater than that of proteins (70). As with GLP1, postprandial secretion is biphasic, initially stimulated by atropine-sensitive neural projections from the foregut, followed by direct nutrient stimulation in the hindgut (71). PYY ${ }_{1-36}$ is rapidly proteolyzed by DPP4; unlike GLP1, however, the cleaved product, $P_{3-36}$, is bioactive. Like GLP1, PYY delays gastric emptying, contributing to the ileal brake (47).

A role for $\mathrm{PYY}_{3-36}$ in satiation was asserted in a recent set of studies heralding this peptide as a promising antiobesity therapeutic (72, 73). It was reported that peripheral $\mathrm{PYY}_{3-36}$ administration, at doses generating physiologic postprandial blood excursions, reduced food intake and body weight in rats. In humans, i.v. infusion replicating postprandial $\mathrm{PYY}_{3-36}$ concentrations lessened hunger and decreased buffet-meal intake by $36 \%$, without causing nausea, affecting food palatability, or altering fluid intake. The reduced food intake was not followed by compensatory hyperphagia. Interestingly, PYY $3-36$ levels were reported to be lower in obese than in lean persons, consistent with a role in obesity pathogenesis. Moreover, anorexia induced by $\mathrm{PYY}_{3-36}$ was fully intact in obese individuals, in contrast to obesity-associated resistance to the anorectic adiposity hormones leptin and insulin. These findings suggested tantalizing therapeutic potential for $\mathrm{PYY}_{3-36}$ and related peptidomimetics.

However, reports that PYY $3-36$ causes anorexia surprised some investigators, because central administration of either PYY $\mathrm{P}_{1-36}$ or $\mathrm{PYY}_{3-36}$ potently increases food intake (74). To explain this paradox, a mechanistic model was formulated, based on Y receptor subtype selectivity and accessibility (72). PYY ${ }_{1-36}$ activates all Y receptors, and orexigenic effects are predicted from its interactions with Y1R and $\mathrm{Y} 5 \mathrm{R}$, which are expressed in the hypothalamic paraventricular nucleus and are thought to mediate NPY-induced feeding. Accordingly, the feeding effects of central PYY are attenuated in both Y1R-deficient and Y5R-deficient mice (75). PYY $3-36$ selectively activates $\mathrm{Y} 2 \mathrm{R}$ and $\mathrm{Y} 5 \mathrm{R}$, and icv administration of this peptide might increase food intake through Y5R. Circulating PYY $3-36$, however, was hypothesized to gain access selectively to Y2R in the hypothalamic arcuate nucleus, an area believed by some to be accessible to blood. In the hypothalamus, Y2R is a presynaptic autoinhibitory receptor on orexigenic neurons that express both NPY and agoutirelated protein (AGRP), known as NPY/AGRP neurons. Therefore, the model proposes that circulating $\mathrm{PYY}_{3-36}$ reduces food intake by inhibiting NPY/AGRP neurons through Y2R, thereby derepressing adjacent anorectic melanocortin-producing cells, which are inhibited by NPY/AGRP neurons (72). Consistent with this model, the feeding effects of $\mathrm{PYY}_{3-36}$ are abolished by pharmacologic or genetic blockade of Y2R $(61,72,76)$. Furthermore, $\mathrm{PYY}_{3-36}$ administration decreases hypothalamic NPY expression in vivo, and it decreases NPY while increasing $\alpha$-melanocyte-stimulating hormone release from hypothalamic explants. Finally, intra-arcuate injections of $\mathrm{PYY}_{3-36}$ inhibit food intake, whereas diffuse icv injections do the opposite (72).

Despite these findings supporting a hypothalamic mechanism of action of peripherally administered $\mathrm{PYY}_{3-36}, \mathrm{Y} 2 \mathrm{R}$ is also expressed by vagal-afferent terminals (77), and some investigators hypothesize vagal mediation. Supporting this assertion, anorectic effects and arcuate neuronal activation elicited by peripheral PYY $3-36$ were eliminated by either subdiaphragmatic vagotomy or transection of hindbrain-hypothalamic pathways $(60,77)$.

Several laboratories reported difficulties in replicating anorectic effects of peripheral $\mathrm{PYY}_{3-36}$ administration, despite using numerous rodent models, experimental protocols, and chemically validated $\mathrm{PYY}_{3-36}$ preparations (78). However, several other groups have confirmed anorectic and weight-reducing properties of this peptide in rodents $(61,76,79-83)$ and nonhuman primates (84). Because stress reduces food intake, potentially masking additional anorectic effects, differences in the habituation of animals to experimental procedures could explain some of these discrepancies (79), although this does not settle the entire debate. The timing of injections is also important, efficacy being lost at certain times of day. The original mechanistic model based on hypothalamic-Y2R-mediated NPY inhibition predicts that anorectic effects of PYY $3-36$ would be maximal at times when arcuate NPY is elevated. Indeed, the initial findings were reported from rodents that were fasting or in the early dark cycle - times when NPY is naturally induced (72).

In summary, the anorectic effects of peripheral PYY $3-36$ administration in rodents are subtle and vulnerable to vicissitudes of animal handling, as well as the dose, route, and timing of injections. Although this might call into question the pragmatism of PYY-based antiobesity therapeutics, anorectic effects of the peptide seem to be more robust in primates than in rodents, and the findings in humans have been corroborated (70). Nevertheless, some pharmaceutical-industry support for clinical development of intranasal PYY $3-36$ has abated because of insufficient efficacy.

\section{Fat-specific satiation peptides: enterostatin and apolipoprotein A-IV}

Some GI peptides are specifically stimulated by fat ingestion and subsequently regulate intake and/or metabolism of lipids. Enterostatin is a pentapeptide cleaved from procolipase, which is secreted from the exocrine pancreas in response to ingested fats to facilitate their digestion. Procolipase is also produced in the gut and several brain areas pertinent to energy homeostasis (85). Both peripheral and central enterostatin administration decreases dietary fat intake in animals, and enterostatin-receptor antagonists do the opposite (86). The mechanisms underlying these effects seem complex but involve the F1-ATPase $\beta$ subunit as the putative enterostatin receptor (87), with downstream mediators including melanocortins and the 5-hydroxytryptamine (serotonin) receptor $1 \mathrm{~B}$ (88). Unfortunately, enterostatin administration to humans has thus far shown no effects on food intake, appetite, energy expenditure, or body weight (89).

Apolipoprotein A-IV (APO AIV) is a glycoprotein secreted from the intestine in response to fat absorption and chylomicron forma- 


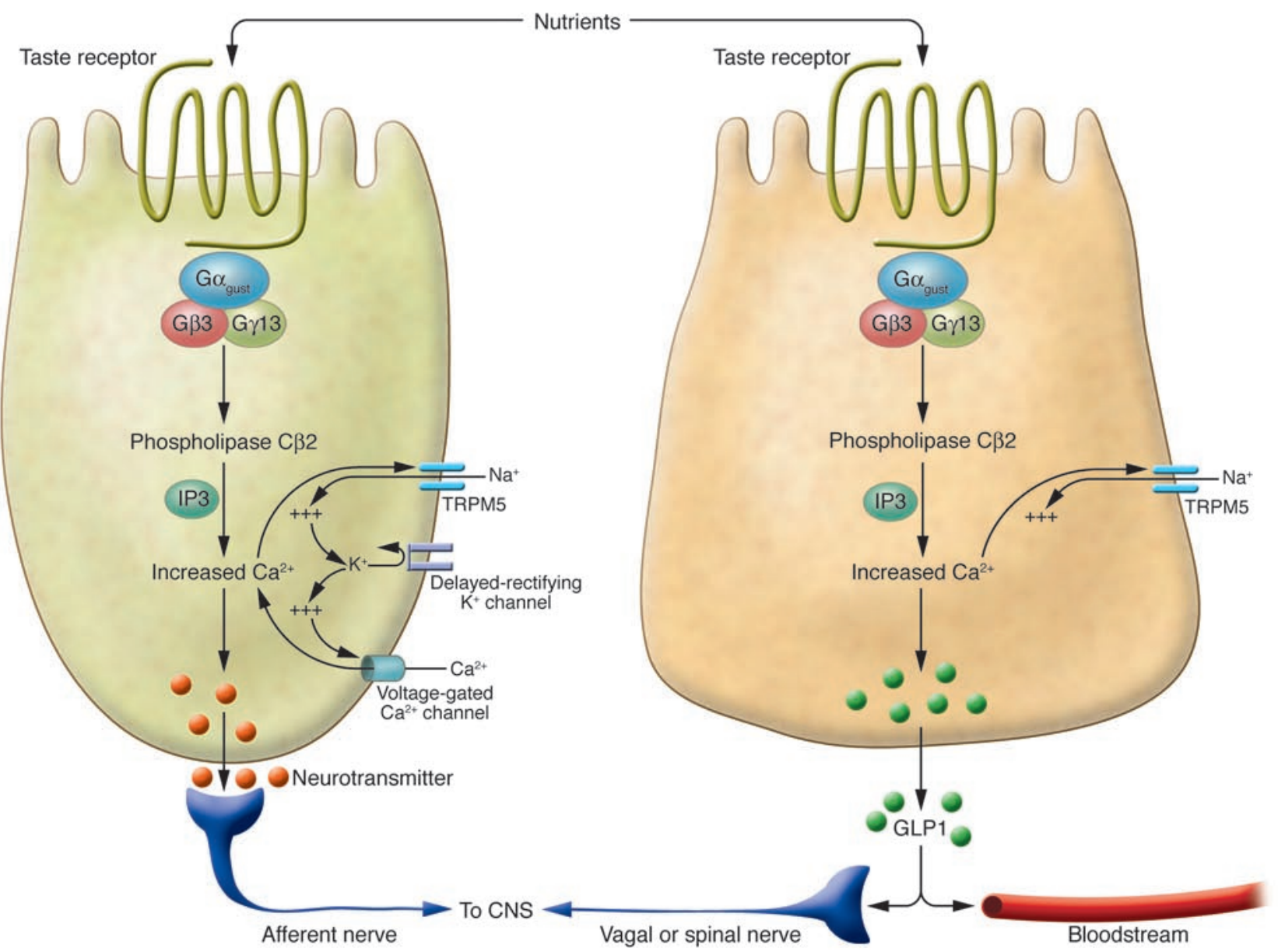

Figure 3

Similarities in nutrient-sensing mechanisms used by taste-receptor cells of the tongue and enteroendocrine cells of the intestine (exemplified by an $\mathrm{L}$ cell). Several types of enteroendocrine cell throughout the gut express components of nutrient-sensing and signal-transduction systems that were previously thought to be selective to taste-bud cells. These include apical G protein-coupled receptors for sweet and bitter chemicals; the unusual $\mathrm{G}$ protein isoforms $\mathrm{G} \alpha_{\text {gustducin, }}, \mathrm{G} \beta 3$, and $\mathrm{G} \gamma 13$; phospholipase $\mathrm{C} \beta 2$; and the TRPM5 $\mathrm{Ca}^{+}{ }^{+}$-activated $\mathrm{Na}^{+} / \mathrm{K}^{+}$channel. Additional contributions from plasma membrane delayed-rectifying $\mathrm{K}^{+}$channels and voltage-gated $\mathrm{Ca}^{2+}$ channels that are important for taste sensation in the tongue have not yet been confirmed in enteroendocrine cells. In both cell types, the final common pathway for activation includes an increase in intracellular calcium concentration. This triggers basolateral exocytosis of neurotransmitters from lingual taste-receptor cells into synapses with nerve fibers that relay information to the hindbrain. In enteroendocrine cells, surges in intracellular calcium concentration trigger release from the basolateral membrane of signaling molecules, including satiation peptides, which diffuse across extracellular fluids to enter the circulation or to interact with nearby afferent nerve terminals from vagal, spinal, and myenteric neurons. IP3, inositol trisphosphate.

tion (90). It is used to package digested lipids for transit through lymphatics to blood. It is also produced in the hypothalamic arcuate nucleus. Exogenous administration of APO AIV decreases meal size, food intake, and weight gain in rats, whereas APO AIV-specific antibodies do the opposite (91). APO AIV is hypothesized to represent a link between short- and long-term regulation of lipidrelated energy balance $(90)$.

\section{Pancreatic satiation peptides: PP and amylin}

$\mathrm{PP}$ is produced in specialized islet cells under vagal control, and its secretion is stimulated postprandially in proportion to caloric load (92). Acting primarily on peripheral and central Y4R and Y5R, it influences biliary and exocrine pancreatic function, gastric acid secretion, and GI motility. Whether PP has an important role in energy homeostasis is controversial, in part because peripheral administration decreases feeding, whereas central administration increases it. Reminiscent of PYY, this disparity might result from differential access to $Y$ receptors - circulating PP decreasing food intake through Y4R in the AP and central PP increasing it through Y5R deeper in the brain. Peripheral PP injections reduce food intake and weight gain in wild-type and genetically obese $o b / o b$ mice (93), and administration to humans decreases appetite and food intake, independently of gastric emptying (94).

Amylin, a peptide cosecreted with insulin postprandially by pancreatic $\beta$ cells, inhibits gastric emptying, gastric acid, and glucagon secretion. It can also decrease meal size and food intake after 
peripheral or central administration $(95,96)$. In contrast to the peripheral neural mechanisms engaged by many gut peptides, amylin is a hormone that functions primarily on the AP (97). The synthetic amylin analogue pramlintide is marketed for diabetes treatment but also causes mild progressive weight loss for at least 26 weeks in humans (98).

\section{Ghrelin: a unique orexigenic hormone}

Ghrelin, an acylated peptide produced primarily by the stomach and proximal small intestine, functions and is regulated oppositely to satiation peptides (99). It powerfully increases food intake in diverse species (100), including humans (101), the only known hormone to do so. Contrary to satiation peptides, ghrelin increases GI motility and decreases insulin secretion. Also in contrast to satiation peptides, circulating levels surge shortly before meals and are suppressed by ingested nutrients (with carbohydrates being more effective than proteins, which are more effective than lipids). Postprandial suppression does not require luminal nutrient exposure in either the stomach or the duodenum, where $80 \%-90 \%$ of ghrelin production occurs, but results instead from neurally transmitted (nonvagal) intestinal signals, augmented by insulin (99).

Ghrelin is implicated in mealtime hunger and meal initiation because of its marked pre-meal surges (102). Moreover, ghrelin enhances food intake by increasing the number of meals initiated, without altering their size, and it elicits numerous appetitive feeding behaviors. Preprandial ghrelin secretion seems to be a cephalic response, possibly stimulated by the sympathetic nervous system (103). Pre-meal ghrelin surges can be entrained to regularly scheduled meals, and they might participate in the anticipatory processes that enable animals to prepare for food intake and nutrient disposition (104).

Beyond its proposed role in short-term feeding control, ghrelin also fulfills established criteria for a hormone contributing to longterm body-weight regulation (99). First, circulating levels respond in a compensatory manner to bidirectional body-weight changes achieved by diverse means, increasing with weight loss and vice versa. Second, ghrelin influences neuronal activity through its receptor in several areas of the brain governing long-term energy homeostasis, including the hypothalamus (specifically arcuate NPY/AGRP neurons), caudal brainstem, and mesolimbic reward centers. The ghrelin receptor is also expressed by vagal-afferent nerves, which are inhibited by ghrelin (opposite to satiation factors) (105), although the importance of this for ghrelin-stimulated feeding is controversial. Third, chronic ghrelin administration increases body weight through numerous anabolic effects on food intake, energy expenditure, and fuel utilization. Finally, pharmacologic ghrelin blockade in adult animals decreases food intake and body weight, and mice lacking ghrelin signaling resist diet-induced obesity $(106,107)$.

Because the obesity-resistant phenotypes of congenital ghrelindeficient and ghrelin receptor-deficient mice are subtle, the relative importance of ghrelin in energy homeostasis remains unclear, and its efficacy as an antiobesity drug target is as yet unproven in humans. Regardless of how physiologically vital ghrelin is in energy homeostasis, however, it offers exciting potential for pharmacologic treatment of cachexia and GI motility disorders.

\section{Mechanisms governing nutrient-stimulated peptide secretion from enteroendocrine cells}

The mechanisms by which food triggers release of GI satiation factors are more diverse than originally described and deserve special attention. Various properties of food stimulate enteroendocrine cells to secrete peptides that diffuse across the subepithelial lamina propria to activate vagal-, enteric-, and spinal-afferent nerves and/or to enter the circulation (Figure 2). One mechanism mediating enteroendocrine cell activation, which regulates GLP1 release, involves cellular uptake and intracellular metabolism of glucose. This triggers peptide exocytosis via ATP-sensitive potassiumchannel closure, depolarization, and calcium-channel activation - analogous to insulin secretion (108).

However, intestinal satiation and enteroendocrine cell activation can occur without nutrient uptake or intracellular metabolism $(14,109)$, by mechanisms resembling oral taste sensation (Figure $3)$. Both taste-receptor cells on the tongue and enteroendocrine cells in the gut are polarized, with apical microvilli bearing receptors that detect chemical properties of food. In response to nutrients, signaling molecules are secreted from the basolateral sides of both cell types, activating adjacent nerve terminals. Several enteroendocrine cell types throughout the gut express T1R2/3 sweet taste receptors, T2R-family bitter receptors, and/or the taste-specific $G$ protein $G \alpha_{\text {gustducin }}$, and these cells are activated by tastant molecules (110-114). For example, intestinal L cells, which secrete GLP1, oxyntomodulin, and PYY, express specialized isoforms of molecules constituting a pathway for nutrient sensing and signal transduction previously believed to be limited to taste-bud cells. These components include sweet and bitter taste receptors; the G protein subunits $\alpha_{\text {gustducin }}, \beta_{3}$, and $\gamma_{13}$; phospholipase $C \beta 2$ (which increases intracellular $\left.\mathrm{Ca}^{2+}\right)$; and the TRPM5 $\mathrm{Ca}^{2+}$-activated $\mathrm{Na}^{+}$/ $\mathrm{K}^{+}$channel (which depolarizes cells) (114). Importantly, taste-like nutrient sensing is necessary for normal GLP1 secretion. The GLP1 response to both glucose and lipid gavage is absent in $\mathrm{G}_{\text {gustducin- }}{ }^{-}$ deficient mice, which consequently manifest impaired incretinmediated insulin secretion (115). In addition to stimulating peptide release directly, sweet-taste-receptor activation by extracellular tastants also upregulates glucose transporters in enteroendocrine cells, possibly amplifying release of satiation peptides by enhancing intracellular glucose uptake and metabolism (110).

Because the details of sweet-taste-receptor activation are understood at the atomic level, one can imagine rational design of noncaloric artificial sweeteners optimized for the combination of palatable taste and potent $\mathrm{L}$ cell activation. These might supplement treatment of obesity and diabetes. Indeed, the nonabsorbable sweetener sucralose stimulates GLP1 release by taste receptor-dependent mechanisms (115).

CCK-producing STC-1 cells also express sweet and bitter taste receptors, along with $\mathrm{G} \alpha_{\text {gustducin }}$ (110), and they respond to bitter tastants with intracellular $\mathrm{Ca}^{2+}$ spikes and CCK release (113). This fits with the strong CCK-stimulating ability of proteins, insofar as bitterness in food derives disproportionately from proteins. Proteins also activate enteroendocrine cells through the extracellular $\mathrm{Ca}^{2+}$-sensing $\mathrm{G}$ protein-coupled receptor (18), which recognizes the aromatic amino acids tryptophan and phenylalanine - residues that elicit intestinal satiation more effectively than other amino acids (116). An interesting, unanswered question is whether the umami receptor, which mediates protein taste sensation in the tongue, contributes to enteroendocrine-cell protein detection. Similarly, we wonder whether the ion channel salty and sour taste-bud receptors, which are directly gated by $\mathrm{Na}^{+}$and $\mathrm{H}^{+}$, respectively, might contribute to gut sensing of ionic and acidic properties of food.

Lipids effectively stimulate many satiation peptides, including CCK, GLP1, oxyntomodulin, PYY, enterostatin, and APO AIV. 


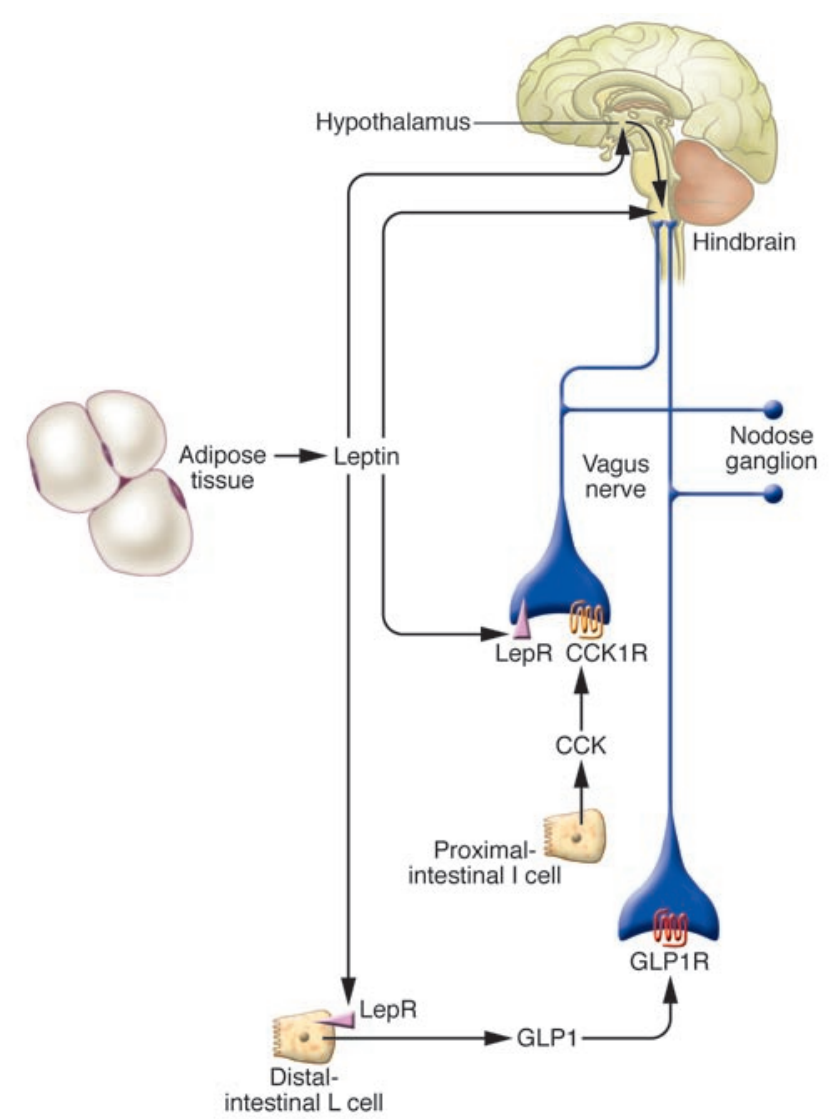

Fatty acids (FAs) must contain at least 12 carbons to activate I cells and stimulate CCK release (117); similarly, only long-chain FAs elicit intestinal satiation (116). Enteroendocrine cells sense FAs in part through the recently deorphanized receptor GPR120. This cell-surface FA receptor is abundantly expressed on intestinal L cells, and it contributes to FA-induced GLP1 secretion (118). Further research is needed to determine whether the FA receptors GPR40-GPR43 are also involved, and whether enteroendocrine cells detect lipids, as the tongue does, via the newly identified putative fat-taste receptor cofactor CD36 (119).

\section{Interactions among long-term adiposity signals and short-term satiation signals}

Long-acting adiposity hormones that regulate body weight, such as leptin and insulin, must ultimately influence eating behavior at individual meals. Accordingly, leptin and insulin acting in the brain, especially the hypothalamus, enhance central sensitivity to input from short-acting peripheral satiation signals, such as CCK (10, 11). Emerging evidence suggests that analogous synergism between long- and short-acting signals occurs in the gut (Figure 4). For example, leptin and insulin receptors are expressed on L cells, and activation of these receptors augments GLP1 secretion (120). Conversely, and similarly to what occurs in the hypothalamus, L cells display diet-induced leptin and insulin resistance, with diminished GLP1 release. These findings suggest that long- and short-acting anorectic signals cooperate at the level of gut-peptide secretion.

Similar interactions occur at the level of vagal sensitivity to gut peptides. A functional signaling isoform of the leptin receptor is coexpressed with CCK1R by vagal-afferent nerve terminals in the

\section{Figure 4}

Central and peripheral sites at which the long-acting adiposity hormone leptin potentiates the actions of short-acting GI satiation factors. Leptin-receptor signaling within the hypothalamus indirectly augments hindbrain neuronal responses to gut satiation signals, such as CCK, through hypothalamus-hindbrain projections involving oxytocin and other neuropeptides $(10,11)$. Central responses to CCK are also augmented by leptin acting directly on the hindbrain. In the periphery, leptin potentiates GI satiation signals both by enhancing gut-peptide secretion (for example, GLP1 release from distal-intestinal L cells) and by heightening vagal-afferent responsiveness to gut peptides (for example, to CCK from proximal-intestinal I cells). LepR, leptin receptor.

stomach and duodenum (121). CCK activation of cultured vagal sensory neurons from these regions is enhanced by leptin (122), and the two peptides function synergistically to increase discharge of vagalafferent fibers (123), just as they potentiate the anorectic actions of each other $(10,11)$. Some authors speculate that these findings establish a neuroanatomical substrate for complementary interactions between gastric leptin and intestinal CCK in short-term satiation. It is probably true that the gastric leptin secreted from chief cells into the stomach lumen during meals travels to the duodenum and stimulates CCK release (124). It is not clear, however, whether gastric leptin secreted from $P$ cells into the circulation reaches duodenal vagal fibers before passing through the liver and being diluted in the general circulation, where leptin levels fluctuate only very minimally with meals. Therefore, the enhancement of CCK-induced duodenal vagal-afferent signaling by leptin might reflect a long-acting adiposity hormone (adipocyte leptin) increasing peripheral neural sensitivity to a short-acting GI satiation factor.

Just as the hypothalamus and hindbrain integrate input from catabolic and anabolic peripheral signals reflecting energy status, the vagus nerve seems to perform an analogous assimilative role in the gut. GI vagal-afferent fibers display extensive colocalization of receptors for gut peptides that are anorexigenic, such as CCK and leptin, as well as orexigenic, such as ghrelin, melaninconcentrating hormone $(\mathrm{MCH})$, and orexins (125). At least some of these receptors are regulated adaptively by alterations in nutritional state, and they interact with one another in a coordinated, logical manner. For example, receptors for ghrelin and CCK are coexpressed on vagal-afferent neurons (125), and these two ligands exert antagonistic effects on vagal-afferent discharges (105). Similarly, catabolic gut peptides tend to suppress secretion of anabolic gut peptides and vice versa, whereas ghrelin increases expression of orexigenic cannabinoid- 1 and $\mathrm{MCH}-1$ receptors on vagal afferents (125). These observations suggest that GI peptides act in a coordinated manner, belying their diffuse anatomical distribution. Moreover, alterations in nutritional state influence gut-brain satiation signaling by recalibrating vagal sensitivity to GI signals.

\section{Hopes for the future}

The elegantly interconnected mechanisms by which the GI system regulates food intake are a marvel of biology, but the redundancy of both GI and CNS pathways governing energy homeostasis poses formidable challenges for scientists designing antiobesity pharmaceuticals. Fortunately, our increasingly sophisticated understanding of these regulatory networks should facilitate the rational manipulation of their components to treat obesity, although it may be necessary to influence more than one element of the system jointly to achieve major weight reduction. Mounting evi- 
dence indicates that the ability of certain bariatric operations to promote profound weight loss and completely resolve type 2 diabetes results, in part, from their salutary modulation of several gut peptides. These changes include stimulation of GLP1, PYY, and oxyntomodulin, constraint of ghrelin secretion, and probably other salient endocrine alterations. Continued research should increasingly enable us to exploit these natural appetite-regulatory systems pharmacologically to achieve at least some of the impressive effects of bariatric surgery with medications.

\section{Acknowledgments}

This work was supported by NIH grants RO1 DK61516 and PO1 DK68384 (to D.E. Cummings).

Address correspondence to: David E. Cummings, University of Washington, VA Puget Sound Health Care System, 1660 South Columbian Way, S-111-Endo, Seattle, Washington 98108, USA. Phone: (206) 764-2335; Fax: (206) 764-2689; E-mail: davidec@ u.washington.edu.
1. Blundell, J.E., and Halford, J.C. 1994. Regulation of nutrient supply: the brain and appetite control. Proc. Nutr. Soc. 53:407-418.

2. Smith, G.P. 1998. Satiation: from gut to brain. Oxford University Press. New York, New York, USA. 291 pp.

3. Strubbe, J.H., and Woods, S.C. 2004. The timing of meals. Psychol. Rev. 111:128-141.

4. Gibbs, J., Young, R.C., and Smith, G.P. 1973. Cholycystokinin elicits satiety in rats with open gastric fistulas. Nature. 245:323-325.

5. Strader, A.D., and Woods, S.C. 2005. Gastrointestinal hormones and food intake. Gastroenterology. 128:175-191.

6. Janowitz, H.D., and Grossman, M.I. 1949. Effect of variations in nutritive density on intake of food of dogs and rats. Am. J. Physiol. 158:184-193.

7. Woods, S.C. 1991. The eating paradox: how we tolerate food. Psychol. Rev. 98:488-505.

8. Grill, H.J., and Norgren, R. 1978. Chronically decerebrate rats demonstrate satiation but not bait shyness. Science. 201:267-269.

9. Grill, H.J., and Smith, G.P. 1988. Cholecystokinin decreases sucrose intake in chronic decerebrate rats. Am. J. Physiol. 254:R853-R856.

10. Schwartz, M.W., Woods, S.C., Porte, D., Jr., Seeley, R.J., and Baskin, D.G. 2000. Central nervous system control of food intake. Nature. 404:661-671.

11. Morton, G.J., Cummings, D.E., Baskin, D.G., Barsh, G.S., and Schwartz, M.W. 2006. Central nervous system control of food intake and body weight. Nature. 443:289-295.

12. Prechtl, J.C., and Powley, T.L. 1990. The fiber composition of the abdominal vagus of the rat. Anat. Embryol. (Berl.) 181:101-115.

13. Davis, J.D., and Smith, G.P. 1990. Learning to sham feed: behavioral adjustments to loss of physiological postingestional stimuli. Am. J. Physiol. 259:R1228-R1235.

14. Ritter, R.C. 2004. Gastrointestinal mechanisms of satiation for food. Physiol. Behav. 81:249-273.

15. Kaplan, J.M., Spector, A.C., and Grill, H.J. 1992. Dynamics of gastric emptying during and after stomach fill. Am. J. Physiol. 263:R813-R819.

16. Powley, T.L., and Phillips, R.J. 2004. Gastric satiation is volumetric, intestinal satiation is nutritive. Physiol. Behav. 82:69-74.

17. Phillips, R.J., and Powley, T.L. 1996. Gastric volume rather than nutrient content inhibits food intake. Am. J. Physiol. 271:R766-R769.

18. Conigrave, A.D., Quinn, S.J., and Brown, E.M. 2000. L-amino acid sensing by the extracellular Ca2+-sensing receptor. Proc. Natl. Acad. Sci. U. S. A. 97:4814-4819.

19. Berthoud, H.R., and Powley, T.L. 1992. Vagal afferent innervation of the rat fundic stomach: morphological characterization of the gastric tension receptor. J. Comp. Neurol. 319:261-276.

20. Phillips, R.J., and Powley, T.L. 2000. Tension and stretch receptors in gastrointestinal smooth muscle: re-evaluating vagal mechanoreceptor electrophysiology. Brain Res. Brain Res. Rev. 34:1-26.

21. Schwartz, G.J., Salorio, C.F., Skoglund, C., and Moran, T.H. 1999. Gut vagal afferent lesions increase meal size but do not block gastric preload-induced feeding suppression. Am. J. Physiol.

\section{6:R1623-R1629.}

22. Gibbs, J., Maddison, S.P., and Rolls, E.T. 1981. Satiety role of the small intestine examined in shamfeeding rhesus monkeys. J. Comp. Physiol. Psychol. 95:1003-1015.

23. Rehfeld, J.F. 2004. A centenary of gastrointestinal endocrinology. Horm. Metab. Res. 36:735-741.

24. Reeve, J.R., Jr., Green, G.M., Chew, P., Eysselein, V.E., and Keire, D.A. 2003. CCK-58 is the only detectable endocrine form of cholecystokinin in rat. Am.J. Physiol. Gastrointest. Liver Physiol. 285:G255-G265.

25. Antin, J., Gibbs, J., Holt, J., Young, R.C., and Smith, G.P. 1975. Cholecystokinin elicits the complete behavioral sequence of satiety in rats. J. Comp. Physiol. Psychol. 89:784-790.

26. Kissileff, H.R., Pi-Sunyer, F.X., Thornton, J., and Smith, G.P. 1981. C-terminal octapeptide of cholecystokinin decreases food intake in man. Am. J. Clin. Nutr. 34:154-160.

27. Moran, T.H., Katz, L.F., Plata-Salaman, C.R., and Schwartz, G.J. 1998. Disordered food intake and obesity in rats lacking cholecystokinin A receptors. Am. J. Physiol. 274:R618-R625.

28. Kopin, A.S., et al. 1999. The cholecystokinin-A receptor mediates inhibition of food intake yet is not essential for the maintenance of body weight. J. Clin. Invest. 103:383-391.

29. Moran, T.H., and Kinzig, K.P. 2004. Gastrointestinal satiety signals. II. Cholecystokinin. Am.J. Physiol. Gastrointest. Liver Physiol. 286:G183-G188.

30. Zittel, T.T., et al. 1999. C-fos protein expression in the nucleus of the solitary tract correlates with cholecystokinin dose injected and food intake in rats. Brain Res. 846:1-11.

31. Smith, G.P., Jerome, C., Cushin, B.J., Eterno, R., and Simansky, K.J. 1981. Abdominal vagotomy blocks the satiety effect of cholecystokinin in the rat. Science. 213:1036-1037.

32. Moran, T.H., Baldessarini, A.R., Salorio, C.F., Lowery, T., and Schwartz, G.J. 1997. Vagal afferent and efferent contributions to the inhibition of food intake by cholecystokinin. Am. J. Physiol. 272:R1245-R1251.

33. Joyner, K., Smith, G.P., and Gibbs, J. 1993. Abdominal vagotomy decreases the satiating potency of CCK-8 in sham and real feeding. Am. J. Physiol. 264:R912-R916.

34. Edwards, G.L., Ladenheim, E.E., and Ritter, R.C. 1986. Dorsomedial hindbrain participation in cholecystokinin-induced satiety. Am. J. Physiol. 251:R971-R977.

35. Blevins, J.E., Stanley, B.G., and Reidelberger, R.D. 2000. Brain regions where cholecystokinin suppresses feeding in rats. Brain Res. 860:1-10.

36. Schwartz, G.J., McHugh, P.R., and Moran, T.H. 1993. Gastric loads and cholecystokinin synergistically stimulate rat gastric vagal afferents. Am. J. Physiol. 265:R872-R876.

37. Moran, T.H., and McHugh, P.R. 1982. Cholecystokinin suppresses food intake by inhibiting gastric emptying. Am. J. Physiol. 242:R491-R497.

38. Kissileff, H.R., Carretta, J.C., Geliebter, A., and Pi-Sunyer, F.X. 2003. Cholecystokinin and stomach distension combine to reduce food intake in humans. Am. J. Physiol. Regul. Integr. Comp. Physiol. 285:R992-R998.
39. Cox, J.E. 1996. Effect of pyloric cuffs on cholecystokinin satiety. Physiol. Behav. 60:1023-1026.

40. Moran, T.H., and Bi, S. 2006. Hyperphagia and obesity in OLETF rats lacking CCK-1 receptors. Philos. Trans. R. Soc. Lond. B Biol. Sci. 361:1211-1218.

41. Moran, T.H., Ameglio, P.J., Peyton, H.J., Schwartz, G.J., and McHugh, P.R. 1993. Blockade of type A, but not type B, CCK receptors postpones satiety in rhesus monkeys. Am. J. Physiol. 265:R620-R624.

42. Reidelberger, R.D., and O'Rourke, M.F. 1989. Potent cholecystokinin antagonist L 364718 stimulates food intake in rats. Am. J. Physiol. 257:R1512-R1518.

43. Beglinger, C., Degen, L., Matzinger, D., D’Amato, M., and Drewe, J. 2001. Loxiglumide, a CCK-A receptor antagonist, stimulates calorie intake and hunger feelings in humans. Am. J. Physiol. Regul. Integr. Comp. Physiol. 280:R1149-R1154.

44. West, D.B., Fey, D., and Woods, S.C. 1984. Cholecystokinin persistently suppresses meal size but not food intake in free-feeding rats. Am. J. Physiol. 246:R776-R787.

45. Muurahainen, N., Kissileff, H.R., Derogatis, A.J., and Pi-Sunyer, F.X. 1988. Effects of cholecystokinin-octapeptide (CCK-8) on food intake and gastric emptying in man. Physiol. Behav. 44:645-649.

46. Crawley, J.N., and Beinfeld, M.C. 1983. Rapid development of tolerance to the behavioural actions of cholecystokinin. Nature. 302:703-706.

47. Pironi, L., et al. 1993. Fat-induced ileal brake in humans: a dose-dependent phenomenon correlated to the plasma levels of peptide YY. Gastroenterology. 105:733-739.

48. Drucker, D.J. 2006. The biology of incretin hormones. Cell Metab. 3:153-165.

49. Brubaker, P.L., and Anini, Y. 2003. Direct and indirect mechanisms regulating secretion of glucagonlike peptide- 1 and glucagon-like peptide-2. Can.J. Physiol. Pharmacol. 81:1005-1012.

50. Orskov, C., Wettergren, A., and Holst, J.J. 1993. Biological effects and metabolic rates of glucagonlike peptide-1 7-36 amide and glucagonlike peptide-1 7-37 in healthy subjects are indistinguishable. Diabetes. 42:658-661.

51. Turton, M.D., et al. 1996. A role for glucagon-like peptide- 1 in the central regulation of feeding. Nature. 379:69-72.

52. Donahey, J.C., van Dijk, G., Woods, S.C., and Seeley, R.J. 1998. Intraventricular GLP-1 reduces shortbut not long-term food intake or body weight in lean and obese rats. Brain Res. 779:75-83.

53. Verdich, C., et al. 2001. A meta-analysis of the effect of glucagon-like peptide-1 (7-36) amide on ad libitum energy intake in humans. J. Clin. Endocrinol. Metab. 86:4382-4389.

54. Gutzwiller,J.P., et al. 1999. Glucagon-like peptide-1: a potent regulator of food intake in humans. Gut. 44:81-86.

55. Naslund, E., et al. 1999. Energy intake and appetite are suppressed by glucagon-like peptide-1 (GLP-1) in obese men. Int. J. Obes. Relat. Metab. Disord. 23:304-311.

56. Toft-Nielsen, M.B., Madsbad, S., and Holst, J.J. 1999. Continuous subcutaneous infusion of glucagon-like peptide 1 lowers plasma glucose and reduces appetite in type 2 diabetic patients. Diabetes 
Care. 22:1137-1143.

57. Zander, M., Madsbad, S., Madsen, J.L., and Holst, J.J. 2002. Effect of 6-week course of glucagon-like peptide 1 on glycaemic control, insulin sensitivity, and beta-cell function in type 2 diabetes: a parallelgroup study. Lancet. 359:824-830.

58. Henry, R., et al. 2006. Exenatide maintained glycemic control with associated weight reduction over 2 years in patients with type 2 diabetes [abstract]. In 66th Scientific Sessions of the American Diabetes Association. June 9-13, 2006. Washington, DC, USA. 485-P.

59. Baggio, L.L., Huang, Q., Brown, T.J., and Drucker, D.J. 2004. Oxyntomodulin and glucagon-like peptide-1 differentially regulate murine food intake and energy expenditure. Gastroenterology. 127:546-558

60. Abbott, C.R., et al. 2005. The inhibitory effects of peripheral administration of peptide YY(3-36) and glucagon-like peptide- 1 on food intake are attenuated by ablation of the vagal-brainstem-hypothalamic pathway. Brain Res. 1044:127-131.

61. Talsania, T., Anini, Y., Siu, S., Drucker, D.J., and Brubaker, P.L. 2005. Peripheral exendin-4 and peptide YY(3-36) synergistically reduce food intake through different mechanisms in mice. Endocrinology. 146:3748-3756.

62. Kinzig, K.P., D’Alessio, D.A., and Seeley, R.J. 2002. The diverse roles of specific GLP-1 receptors in the control of food intake and the response to visceral illness. J. Neurosci. 22:10470-10476.

63. Scrocchi, L.A., et al. 1996. Glucose intolerance but normal satiety in mice with a null mutation in the glucagon-like peptide 1 receptor gene. Nat. Med. 2:1254-1258.

64. Dakin, C.L., et al. 2001. Oxyntomodulin inhibits food intake in the rat. Endocrinology. 142:4244-4250.

65. Dakin, C.L., et al. 2004. Peripheral oxyntomodulin reduces food intake and body weight gain in rats. Endocrinology. 145:2687-2695.

66. Cohen, M.A., et al. 2003. Oxyntomodulin suppresses appetite and reduces food intake in humans. J. Clin. Endocrinol. Metab. 88:4696-4701.

67. Wynne, K., et al. 2005. Subcutaneous oxyntomodulin reduces body weight in overweight and obese subjects: a double-blind, randomized, controlled trial. Diabetes. 54:2390-2395.

68. Wynne, K., et al. 2006. Oxyntomodulin increases energy expenditure in addition to decreasing energy intake in overweight and obese humans: a randomised controlled trial. Int. J. Obes. (Lond.). 30:1729-1736.

69. Yamamoto, H., et al. 2002. Glucagon-like peptide-1 receptor stimulation increases blood pressure and heart rate and activates autonomic regulatory neurons. J. Clin. Invest. 110:43-52. doi:10.1172/ JCI200215595.

70. Degen, L., et al. 2005. Effect of peptide YY336 on food intake in humans. Gastroenterology. 129:1430-1436.

71. Lin, H.C., and Taylor, I.L. 2004. Release of peptide YY by fat in the proximal but not distal gut depends on an atropine-sensitive cholinergic pathway. Regul. Pept. 117:73-76.

72. Batterham, R.L., et al. 2002. Gut hormone PYY(3 36) physiologically inhibits food intake. Nature. 418:650-654

73. Batterham, R.L. 2003. Inhibition of food intake in obese subjects by peptide YY3-36. N. Engl. J. Med. 349:941-948

74. Hagan, M.M. 2002. Peptide YY: a key mediator of orexigenic behavior. Peptides. 23:377-382.

75. Kanatani, A., et al. 2000. Role of the Y1 receptor in the regulation of neuropeptide Y-mediated feeding: comparison of wild-type, $\mathrm{Y} 1$ receptor-deficient, and Y5 receptor-deficient mice. Endocrinology. 141:1011-1016.

76. Scott, V., Kimura, N., Stark, J.A., and Luckman,
S.M. 2005. Intravenous peptide YY3-36 and Y2 receptor antagonism in the rat: effects on feeding behaviour. J. Neuroendocrinol. 17:452-457.

77. Koda, S., et al. 2005. The role of the vagal nerve in peripheral PYY3-36-induced feeding reduction in rats. Endocrinology. 146:2369-2375.

78. Tschop, M., et al. 2004. Physiology: does gut hormone PYY3-36 decrease food intake in rodents? Nature. 430:1 p following 165; discussion $2 \mathrm{p}$ following 165.

79. Halatchev, I.G., Ellacott, K.L., Fan, W., and Cone, R.D. 2004. Peptide YY3-36 inhibits food intake in mice through a melanocortin-4 receptor-independent mechanism. Endocrinology. 145:2585-2590.

80. Adams, S.H., Won, W.B., Schonhoff, S.E., Leiter, A.B., and Paterniti, J.R., Jr. 2004. Effects of peptide YY[3-36] on short-term food intake in mice are not affected by prevailing plasma ghrelin levels. Endocrinology. 145:4967-4975.

81. Challis, B.G., et al. 2004. Mice lacking POMC are sensitive to high-fat feeding but respond normally to the acute anorectic effects of peptide-YY(3-36). Proc. Natl. Acad. Sci. U. S. A. 101:4695-4700.

82. Pittner, R.A., et al. 2004. Effects of PYY[3-36] in rodent models of diabetes and obesity. Int. J. Obes. Relat. Metab. Disord. 28:963-971.

83. Chelikani, P.K., Haver, A.C., Reeve, J.R., Jr., Keire, D.A., and Reidelberger, R.D. 2006. Daily, intermittent intravenous infusion of peptide YY(3-36) reduces daily food intake and adiposity in rats. Am.J. Physiol. Regul. Integr. Comp. Physiol. 290:R298-R305.

84. Moran, T.H., et al. 2005. Peptide YY(3-36) inhibits gastric emptying and produces acute reductions in food intake in rhesus monkeys. Am. J. Physiol. Regul. Integr. Comp. Physiol. 288:R384-R388.

85. York, D.A., Lin, L., Thomas, S.R., Braymer, H.D., and Park, M. 2006. Procolipase gene expression in the rat brain: source of endogenous enterostatin production in the brain. Brain Res. 1087:52-59.

86. Okada, S., York, D.A., Bray, G.A., Mei, J., and Erlanson-Albertsson, C. 1992. Differential inhibition of fat intake in two strains of rat by the peptide enterostatin. Am. J. Physiol. 262:R1111-R1116.

87. Park, M., et al. 2004. The F1-ATPase beta-subunit is the putative enterostatin receptor. Peptides. 25:2127-2133

88. Lin, L., and York, D.A. 2005. 5-HT1B receptors modulate the feeding inhibitory effects of enterostatin. Brain Res. 1062:26-31.

89. Kovacs, E.M., Lejeune, M.P., and Westerterp-Plantenga, M.S. 2003. The effects of enterostatin intake on food intake and energy expenditure. Br. J. Nutr. 90:207-214.

90. Qin, X., and Tso, P. 2005. The role of apolipoprotein AIV in the control of food intake. Curr. Drug Targets. 6:145-151

91. Fujimoto, K., Fukagawa, K., Sakata, T., and Tso, P. 1993. Suppression of food intake by apolipoprotein A-IV is mediated through the central nervous system in rats. J. Clin. Invest. 91:1830-1833.

92. Katsuura, G., Asakawa, A., and Inui, A. 2002. Roles of pancreatic polypeptide in regulation of food intake. Peptides. 23:323-329.

93. Asakawa, A., et al. 2003. Characterization of the effects of pancreatic polypeptide in the regulation of energy balance. Gastroenterology. 124:1325-1336.

94. Batterham, R.L., et al. 2003. Pancreatic polypeptide reduces appetite and food intake in humans. J. Clin. Endocrinol. Metab. 88:3989-3992.

95. Rushing, P.A., Hagan, M.M., Seeley, R.J., Lutz, T.A., and Woods, S.C. 2000. Amylin: a novel action in the brain to reduce body weight. Endocrinology. 141:850-853.

96. Lutz, T.A., Geary, N., Szabady, M.M., Del Prete, E., and Scharrer, E. 1995. Amylin decreases meal size in rats. Physiol. Behav. 58:1197-1202.

97. Lutz, T.A., Althaus, J., Rossi, R., and Scharrer, E. 1998. Anorectic effect of amylin is not transmitted by capsaicin-sensitive nerve fibers. Am. J. Physiol. 274:R1777-R1782.

98. Hollander, P., et al. 2004. Effect of pramlintide on weight in overweight and obese insulin-treated type 2 diabetes patients. Obes. Res. 12:661-668.

99. Cummings, D.E., Foster-Schubert, K.E., and Overduin, J. 2005. Ghrelin and energy balance: focus on current controversies. Curr. Drug Targets. 6:153-169.

100.Tschop, M., Smiley, D.L., and Heiman, M.L. 2000. Ghrelin induces adiposity in rodents. Nature. 407:908-913.

101. Wren, A.M., et al. 2001. Ghrelin enhances appetite and increases food intake in humans. J. Clin. Endocrinol. Metab. 86:5992-5995.

102. Cummings, D.E., et al. 2002. Plasma ghrelin levels after diet-induced weight loss or gastric bypass surgery. N. Engl. J. Med. 346:1623-1630.

103.Mundinger, T.O., Cummings, D.E., and Taborsky, G.J., Jr. 2006. Direct stimulation of ghrelin secretion by sympathetic nerves. Endocrinology. 147:2893-2901

104.Drazen, D.L., Vahl, T.P., D’Alessio, D.A., Seeley, R.J., and Woods, S.C. 2006. Effects of a fixed meal pattern on ghrelin secretion: evidence for a learned response independent of nutrient status. Endocrinology. 147:23-30.

105. Date, Y., et al. 2002. The role of the gastric afferent vagal nerve in ghrelin-induced feeding and growth hormone secretion in rats. Gastroenterology. 123:1120-1128

106. Wortley, K.E., et al. 2005. Absence of ghrelin protects against early-onset obesity. J. Clin. Invest. 115:3573-3578. doi:10.1172/JCI26003

107.Zigman, J.M., et al. 2005. Mice lacking ghrelin receptors resist the development of diet-induced obesity. J. Clin. Invest. 115:3564-3572. doi:10.1172/ JCI26002.

108. Reimann, F., and Gribble, F.M. 2002. Glucose-sensing in glucagon-like peptide-1-secreting cells. Diabetes. 51:2757-2763.

109.Gribble, F.M., Williams, L., Simpson, A.K., and Reimann, F. 2003. A novel glucose-sensing mechanism contributing to glucagon-like peptide-1 secretion from the GLUTag cell line. Diabetes. 52:1147-1154.

110.Dyer, J., Salmon, K.S., Zibrik, L., and Shirazi-Beechey, S.P. 2005. Expression of sweet taste receptors of the $\mathrm{T} 1 \mathrm{R}$ family in the intestinal tract and enteroendocrine cells. Biochem. Soc. Trans. 33:302-305.

111.Wu, S.V., et al. 2002. Expression of bitter taste receptors of the T2R family in the gastrointestinal tract and enteroendocrine STC-1 cells. Proc. Natl. Acad. Sci.U. S. A. 99:2392-2397.

112. Hofer, D., Puschel, B., and Drenckhahn, D. 1996. Taste receptor-like cells in the rat gut identified by expression of alpha-gustducin. Proc. Natl. Acad. Sci. U. S. A. 93:6631-6634

113.Chen, M.C., Wu, V., Reeve, J.R., and Rozengurt, E. 2006. Bitter stimuli induce Ca2+ signaling and CCK release in enteroendocrine STC-1 cells: role of L-type voltage-sensitive Ca2+ channels. Am. J. Physiol. Cell Physiol. 291:C726-C739.

114.Rozengurt, N., et al. 2006. Colocalization of the alpha-subunit of gustducin with PYY and GLP-1 in L cells of human colon. Am. J. Physiol. Gastrointest. Liver Physiol. 291:G792-G802.

115.Margolskee, R.F. 2006. Molecular biology of taste perception. Diabetes. 55(Suppl. 1):35.

116.Meyer, J.H., Hlinka, M., Tabrizi, Y., DiMaso, N., and Raybould, H.E. 1998. Chemical specificities and intestinal distributions of nutrient-driven satiety. Am. J. Physiol. 275:R1293-R1307.

117. McLaughlin, J., et al. 1999. Fatty acid chain length determines cholecystokinin secretion and effect on human gastric motility. Gastroenterology. 116:46-53.

118. Hirasawa, A., et al. 2005. Free fatty acids regulate gut incretin glucagon-like peptide-1 secretion through GPR120. Nat. Med. 11:90-94.

119.Laugerette, F., et al. 2005. CD36 involvement in 
orosensory detection of dietary lipids, spontaneous fat preference, and digestive secretions. J. Clin. Invest. 115:3177-3184. doi:10.1172/JCI25299.

120.Anini, Y., and Brubaker, P.L. 2003. Role of leptin in the regulation of glucagon-like peptide-1 secretion. Diabetes. 52:252-259.

121.Burdyga, G., et al. 2002. Expression of the leptin receptor in rat and human nodose ganglion neurones. Neuroscience. 109:339-347.
122.Peters, J.H., Karpiel, A.B., Ritter, R.C., and Simasko, S.M. 2004. Cooperative activation of cultured vagal afferent neurons by leptin and cholecystokinin. Endocrinology. 145:3652-3657.

123.Wang, Y.H., Tache, Y., Sheibel, A.B., Go, V.L., and Wei, J.Y. 1997. Two types of leptin-responsive gastric vagal afferent terminals: an in vitro single-unit study in rats. Am. J. Physiol. 273:R833-R837.

124.Guilmeau, S., Buyse, M., Tsocas, A., Laigneau, J.P., and Bado, A. 2003. Duodenal leptin stimulates cholecystokinin secretion: evidence of a positive leptin-cholecystokinin feedback loop. Diabetes. 52:1664-1672.

125.Burdyga, G., Varro, A., Dimaline, R., Thompson, D.G., and Dockray, G.J. 2006. Ghrelin receptors in rat and human nodose ganglia: putative role in regulating CB-1 and $\mathrm{MCH}$ receptor abundance. Am.J. Physiol. Gastrointest. Liver Physiol. 290:G1289-G1297. 